\title{
Rafael Humberto Moreno-Durán y RAFAEl GutiérREZ Girardot: LA CORRESPONDENCIA DE UN ESCRITOR Y SU CRÍTICO LITERARIO*
}

\author{
Rafael Humberto Moreno-Durán \\ and Rafael Gutiérrez Girardot: The \\ Correspondence Between a Writer and \\ his Literary CRitic
}

Diego Alejandro Zuluaga Quintero ${ }^{1}$

\begin{abstract}
* Artículo derivado de la tesis Intercambio epistolar, sociabilidad intelectual hispanoamericana. Rafael Gutiérrez Girardot: Alfonso Reyes, Ángel Rama, Eduardo Mallea, R. H. Moreno Durán del Doctorado en Ciencias Sociales y Humanidades de la Universidad Autónoma Metropolitana, Unidad Cuajimalpa. La tesis fue financiada por el Conacyt. Además, hace parte de la Estrategia de Sostenibilidad 2018-19 de la Vicerrectoría de Investigación de la Universidad de Antioquia.
\end{abstract}

Cómo citar este artículo: Zuluaga Quintero, D. A. (2022). Rafael Humberto MorenoDurán y Rafael Gutiérrez Girardot: la correspondencia de un escritor y su crítico literario. Estudios de Literatura Colombiana 50, pp. 87-105. DOI: https://doi.org/10.17533/ udea.elc.n50a05

${ }^{1}$ https://orcid.org/0000-0001-5110-6938 diego.zuluagaq@udea.edu.co

Universidad de Antioquia, Colombia

Editores: Andrés Vergara Aguirre, Christian Benavides Martínez

Recibido: 15.08 .2021

Aprobado: 27.09.2021

Publicado: 17.01.2022

Copyright: (2022 Estudios de Literatura Colombiana. Este es un artículo de acceso abierto distribuido bajo los términos de la Licencia Creative Commons AtribuciónNo comercial - Compartir igual 4.0 Internacional
Resumen: $\mathrm{El}$ artículo estudia la correspondencia entre Rafael Gutiérrez Girardot y Rafael Humberto Moreno-Durán desde 1977 hasta 2004. El propósito es revelar cómo en esta relación intelectual se buscan proyectos comunes en los que se definen ciertos roles específicos dentro del campo. Como crítico literario, Gutiérrez Girardot desarrolla la función de juzgar y ubicar la obra novelística de Moreno-Durán dentro de la escena de la literatura hispanoamericana. Este último desde su escritura busca posicionarse en el medio literario internacional y media para que el otro divulgue su obra crítica en Colombia y España.

Palabras clave: correspondencia; postboom; crítica literaria; Gutiérrez Girardot; Moreno-Durán.

Abstract: The article studies the correspondence between Rafael Gutiérrez Girardot and Rafael Humberto Moreno-Durán from 1977 to 2004. The purpose is to reveal how, in this intellectual relationship, common projects are sought in which some specific roles are defined within the literary field. As a literary critic, Gutierrez Girardot develops the function of judging and locating Moreno-Durán's novelistic work within the scene of Hispanic American literature. The latter, through his writing, seeks to position himself in the international literary scene and mediates for the other to disseminate his critical work in Colombia and Spain.

Keywords: correspondence; postboom; literary critic; Gutiérrez Girardot; Moreno-Durán. 


\section{Presentación}

Es indudable que la carta de presentación de un intelectual es su obra publicada, es decir, la recepción que tiene en un público determinado; sin embargo, como se mostrará en este caso, es necesario un trabajo extra, pues no es suficiente para los intelectuales publicar este o aquel libro. Se puede decir que las cartas que escriben los intelectuales hacen parte de su tarea. La correspondencia se erige entonces en un medio fundamental para, de manera privada, llamar la atención de otro intelectual respecto de lo que se está haciendo. A través de la correspondencia, los intelectuales avisan a sus colegas sobre sus trabajos recientes o proyectos en desarrollo. En la vida intelectual, la epístola sirve de vínculo y de medio para posicionarse ante el otro, ante sus redes y ante la cultura en general (Myers, 2014-2015, pp. 53-69). ${ }^{1}$ La escritura de las cartas, como dice Mariana Ozuna Castañeda (2017), "materializa las relaciones, al mismo tiempo des-aleja a los individuos, y pone a la escritura como garante de la relación misma” (p. 273). Antes de la era digital, la carta era uno de los principales medios para dinamizar la vida intelectual. Incluso las cartas pueden convertirse en laboratorio o adelanto de reflexiones o génesis de ensayo. Estos son los aspectos que se analizan de las cartas que intercambiaron los colombianos Rafael Humberto Moreno-Durán y Rafael Gutiérrez Girardot, en las que además se percibe cómo ambos autores legitiman su papel de intelectuales, pues buscan construir a través del diálogo una obra "monumental".

\section{La primera carta y el inicio de una correspondencia fluida}

E1 28 de septiembre de 1977, Rafael Humberto Moreno-Durán escribe una carta a Rafael Gutiérrez Girardot en la que le expresa la curiosidad que desde los dieciséis años había sentido por su personalidad. Desde esa época deseaba saber quién era ese boyacense que había escrito sobre la Fenomenología de Hegel en la revista Mito. Para

Al explorar las cartas de Alfonso Reyes, Jorge Myers resalta que la vida diplomática de Reyes está intrínsecamente relacionada con la construcción de su obra epistolar. Para Myers, la distancia que mantuvo el mexicano durante los más de veinte años de diplomacia es la que da lugar a la construcción de una red intelectual y epistolar única en el continente americano. Myers muestra que Reyes escribió epístolas a los dos costados del mundo y caracteriza sus cartas como pequeños tratados de reflexión humanística. De este modo la correspondencia es un medio utilizado para el debate intelectual y la definición del propio pensamiento frente al pensamiento del destinatario. Además, las cartas son utilizadas para extender el campo de acción de los corresponsales al publicarlos y promoverlos en otras latitudes. Gutiérrez Girardot fue diplomático antes de llegar a la Universidad de Bonn, pero en la universidad seguía realizando labores de agregaduría cultural desde Alemania para América Latina y en este sentido el estudio de Myers es un referente. 
Moreno-Durán era todo un misterio ese personaje atrapado por la cultura alemana del que nadie daba noticias acertadas en Colombia. Quería saber quién era ese personaje que admiraba y con el que se sentía identificado por el origen geográfico común. Ambos provenían de la misma provincia colombiana y habían estudiado en la Universidad Nacional de Colombia - Moreno-Durán, Derecho y Ciencias Políticas; Gutiérrez Girardot, Filosofía (sin graduarse)—. También se sentía identificado con él porque este último había estudiado Derecho en la Universidad el Rosario. De igual manera, los dos colombianos vivían fuera de su país por voluntad propia; el crítico literario en Bonn y el escritor en Barcelona, desde donde inicialmente se escriben la correspondencia. Ambos eran cosmopolitas de origen provinciano: Boyacá, por cierto, provincia muy rural y periférica en el contexto colombiano. Lo anterior tiene mucha importancia al ser el camino de muchos intelectuales colombianos que migran de la provincia, llegan a la capital y luego transmigran a destinos internacionales. Esta fue la constante, por ejemplo, de los intelectuales de la generación de la revista Mito entre los que estaba García Márquez.

El acercamiento de Moreno-Durán a Gutiérrez Girardot se había dado gracias a los trabajos de este que, esporádicamente, llegaban a Colombia: el libro Jorge Luis Borges: Ensayo de interpretación, el estudio sobre Machado, Poesía y prosa en Antonio Machado, algunas incursiones en la literatura latinoamericana y el libro sobre la literatura alemana publicado en Taurus. Moreno-Durán había leído estas publicaciones con mucha curiosidad, pues hasta el año 1977, Rafael Gutiérrez Girardot era una figura conocida solamente por cierta élite intelectual y compañeros de generación en Mito. Esto significa que su presencia en los medios impresos del país era, para la época, de bajo perfil. De esta forma empieza una relación epistolar que durará casi tres décadas, desde la fecha indicada hasta el 2004, poco antes de la muerte de Rafael Gutiérrez Girardot. Es una relación epistolar que, básicamente, define dos roles en el campo intelectual, es decir, es una relación entre escritor y crítico literario. Como crítico, Rafael Gutiérrez Girardot desempeña el papel de mediador entre la obra literaria y el público lector, es quien da los criterios para comprender la obra de R. H. Moreno-Durán dentro de una perspectiva latinoamericana y occidental. En su sentido más especializado, Rafael Gutiérrez Girardot es la persona encargada de definir el buen gusto literario en la apreciación de la obra del otro boyacense (esta es la función que le encarga Moreno-Durán). Es el canal a través del cual el escritor 
espera lograr cierto reconocimiento, pues en la tradición occidental, el crítico es el que ayuda a implantar las glorias literarias, definiendo lo "auténticamente grande” y “desestimando reconocimientos" (Williams, 1980, p. 66). Para R. H. Moreno-Durán, Gutiérrez Girardot era una instancia de consagración. El vínculo entre estos personajes es dinámico y fluido; los papeles llevados a cabo no solo se definen, sino que se combinan. En este caso, el escritor también cumple funciones divulgativas y críticas respecto del profesor de la universidad alemana; Moreno-Durán reseña la producción intelectual de Gutiérrez Girardot y es el editor de algunos de sus libros, pero, sobre todo, le abre las puertas en instituciones culturales donde él tiene una posición asegurada, como es el caso de las revistas españolas Viejo Topo y Quimera, en las que Gutiérrez Girardot publicará muchos de sus ensayos importantes. Ambos autores se permiten y facilitan la mutua divulgación, es decir, esta es también la correspondencia entre dos editores.

Se trata de una relación epistolar intensa. En total, se pueden sumar más de 70 piezas epistolares enviadas por Moreno-Durán a Gutiérrez Girardot. Aunque no se tiene la totalidad de las cartas de Rafael Gutiérrez Girardot a R. H. Moreno-Durán, se puede pensar que entre ambos se escribieron aproximadamente 140 piezas epistolares, ${ }^{2}$ pues todas las cartas escritas por Moreno-Durán eran también respuestas a misivas recibidas por parte de Gutiérrez Girardot. ${ }^{3}$ Esta intensidad se evidencia en una carta que le envía Gutiérrez Girardot a Moreno-Durán en la que expresa: "Casi estamos como Goethe y Schiller, sin ser lo uno ni lo otro, que se escribieron todos los días aunque vivían a la vuelta de la esquina. Cuando le envié hoy mi carta pensé acto seguido iba a escribir otra" (Gutiérrez Girardot, 1981a).

Uno de los motivos de esta intensidad epistolar es, en sus inicios, la publicación y “orientación” de las revistas españolas y el vínculo con la editorial Montesinos. Primero están las revistas Camp de L'Arpa y Viejo topo, pero luego está la revista Quimera. Hay otras publicaciones — menos importantes en este epistolario- en las cuales trabajan ambos autores, pero el diálogo epistolar que analizaremos aquí está relacionado

Las cartas eran en su mayoría mecanuscritas.

3 El material epistolar fue consultado en el archivo personal del profesor Juan Guillermo Gómez García (APJGGG). El profesor Gómez García ha construido este archivo en el proceso de elaboración de la Biografía Intelectual de Gutiérrez Girardot. Él completó sus hallazgos en la Biblioteca Gabriel García Márquez de la Universidad Nacional de Colombia (donde reposa parte de la base documental desde el 2007) con la búsqueda de material empírico en diferentes partes del mundo como España, Alemania, Argentina y Estado Unidos. 
con la construcción en el amplio sentido de la palabra de la obra de Rafael Humberto Moreno-Durán e indirectamente la divulgación del crítico literario primero en España y luego en Colombia.

\section{R. H. Moreno-Durán y Rafael Gutiérrez Girardot: ęuna correspondencia en la construcción de un novelista del postboom latinoamericano?}

Es destacable la fluidez de la relación entre crítico literario y escritor. Esto, precisamente, por ese respeto y admiración que siente Moreno-Durán por la profesión de la crítica literaria. Mientras que muchos escritores han menospreciado esta profesión, Moreno-Durán considera que el escritor debe tener un vínculo estrecho con la crítica literaria para retroalimentar su escritura:

Leo lo que la crítica dice y mi interés es el de extraer de ella algo que me sirva para comprender mejor mis libros y para evitar caer en el futuro en posibles fallos. Respeto la crítica, es triste observar cómo se ha trivializado tanto y cómo todo se reduce a un juego de adjetivos afectuosos que no aporta absolutamente nada (Moreno-Durán, 1978a).

Desde las primeras cartas que Rafael Humberto Moreno-Durán escribe a su amigo expresa el deseo de que Gutiérrez Girardot encarne ese "buscado exegeta", el crítico literario que todo escritor debe tener para "recrear sus posibles aciertos y logros”. Aprender de la crítica es quizás una de las motivaciones más importantes que tiene el escritor para sostener una correspondencia por tan largo tiempo. Por supuesto, Gutiérrez Girardot acepta gustoso la tarea asignada, pues Moreno-Durán agradece "la noticia que da en su última carta, sobre su deseo de escribir sobre mis libros, noticia que me agrada y me sobrecoge, pues su perspicacia crítica es impresionante por lo implacable" (Moreno-Durán, 1978b). Es Gutiérrez Girardot un profesional de la crítica literaria, pues, como ha mostrado Gonzalo Aguilar (2010), esta figura especializada se proyecta en Latinoamérica en los años cincuenta del siglo xx y se afianza en los sesenta y setenta con un "saber académico", "como una figura pública legitimada por su capacidad para interpretar con un método y un arsenal conceptual sofisticado los textos literarios y darles una significación social, cultural y eventualmente política” (p. 685). Este autor se está refiriendo a Ángel Rama, António Cândido y Antonio Cornejo Polar, quienes, entre otros, buscaban precisar "una teoría de la literatura latinoamericana" y superar el ensayismo literario de Alfonso Reyes o Baldomero Sanín Cano, quienes fueron también diplo- 
máticos y burócratas gubernamentales. Nosotros sumamos a Gutiérrez Girardot, que en 1970 pasó de ser un ensayista vinculado por muchos años a la diplomacia Colombia (1956-1967) a alcanzar la cátedra de Hispanística en la Universidad de Bonn, donde podía desarrollar su labor crítica literaria de manera autónoma y como un saber especializado profesional.

Por su parte, Moreno-Durán lee el libro de su amigo Horas de estudio y quiere seguir y entender las sugerencias del que considera su maestro. Moreno-Durán es uno de esos escritores que respeta la crítica literaria y piensa que la lectura de sus trabajos es una muy buena manera de orientar y canalizar la escritura. Para finales del año 1979, Gutiérrez Girardot está ejerciendo su profesión teniendo como base la obra de Moreno-Durán. Es importante aclarar que esta no es una actividad que desarrolla el crítico pasivamente; es decir, no se reduce a la lectura y comentario de la obra. Esta actividad implica, para el crítico literario, un diálogo fluido y dinámico con el escritor. Gutiérrez Girardot comenta, por vía epistolar, las impresiones dejadas por una lectura inicial de Juego de damas (1977), la primera novela de su amigo, y luego procede a hacer un cuestionario orientado a clarificar las dudas que le ha dejado. El cuestionario para el escritor tiene preguntas que van desde el motivo de la dedicatoria - que, en este caso está dirigida a Ludwig Pursewarden - hasta el origen de ciertas palabras muy utilizadas en la obra. Este es el primer paso dado por Gutiérrez Girardot antes de escribir los textos críticos que serán publicados. Por supuesto, Moreno-Durán le agradece la atención a los detalles que un lector desprevenido pasaría por alto.

La relación del escritor con el crítico literario es dinámica y útil, especialmente a los intereses del primero. Gutiérrez Girardot entra en contacto con la editorial alemana Suhrkamp y le promete a Moreno-Durán buscar la forma de publicar su Juego de damas en Alemania. Al respecto, le dice: "Cuando haya hecho el Gutachten sobre Romero [...] le propondré su libro. No es necesario que usted se lo envíe. Envíeme usted un ejemplar, y yo se lo haré llegar. Me interesa que me envíe algunas reseñas positivas o noticias de cualquier clase” (Gutiérrez Girardot, 1980).

Por su parte, en 1981 Moreno-Durán le expresa a Gutiérrez Girardot las buenas nuevas de la novela y la reseña que ha presentado García Ponce en México. Le preocupa que en su país la novela siga sin existir. Pero además le anuncia, para febrero de 1981, la publicación de El toque de Diana, segunda parte de una trilogía. Y luego expresa: "Mi curiosidad por saber lo que piensa usted de mi novela, no tiene límites, 
en serio" (Moreno-Durán, 1981). Todo indica que esta relación se desarrolla en beneficio de la construcción de una carrera intelectual (la de Moreno-Durán), lo que no impide que Gutiérrez Girardot se fortalezca, igualmente, como crítico literario, porque a lo largo de su vida la obra de Moreno-Durán será motivo para pensar, escribir y aparecer en los medios intelectuales a los que tiene acceso el autor que debe analizar críticamente.

En el epistolario se percibe el deseo, por parte de R. H. Moreno-Durán, de que se apuntale el concepto del "Postboom de la literatura latinoamericana" en el que él, desde luego, se incluye al lado de escritores del continente como Alfredo Bryce Echenique o José Emilio Pacheco. Le solicita a Gutiérrez Girardot que escriba sobre el tema para la revista Quimera y que además asista a un congreso donde se tratará el asunto. Allí podrá hablar de Moreno-Durán y la literatura del postboom latinoamericano. Moreno-Durán quiere evitar que en un evento donde se hablará de los herederos de la época dorada de la literatura latinoamericana no haya quien incluya su nombre y hable de su literatura. A lo largo de todo el epistolario se percibe su deseo por ser el heredero comercial de esos escritores que en la década del sesenta y setenta lograron tener ventas exorbitantes y reconocimiento internacional. Es también una especie de fe en que el boom literario va a pasar de moda y luego él será parte de la nueva tendencia literaria. Pero sabe que necesita de la ayuda extrapoética, del crítico y de las conexiones de este.

La construcción de una novelística del postboom significa para estos dos autores una disputa con otros intelectuales por un espacio de atención, en el entendido de que, como dice Randall Collins (2005), en la vida intelectual "hay una lucha por dividir el espacio de atención” (p. 79) porque el número de intelectuales que pueden llamar la atención de las diferentes instancias de legitimación es pequeño. En algunos casos, significa una afrenta para otros colombianos que sienten que esto es una especie de sacrilegio. Por ejemplo, en 1981 es publicado, en el número 14 de Quimera, un artículo de Gutiérrez Girardot sobre Moreno-Durán en el cual el crítico, de alguna manera, le sigue el juego al escritor. En el texto se hace una comparación entre El Toque de Diana y Crónica de una muerte anunciada, dos novelas colombianas que se publicaron con tres meses de diferencia y cuyo contraste más radical es el hecho de que la novela de García Márquez cuenta con todo el aparato publicitario y editorial. La última es una novela que tiene la apología asegurada gracias a la importancia y grandeza de 
Cien años de soledad, mientras que la otra novela tiene asegurada la "indiferencia" y, posiblemente, "algunos juicios críticos positivos". Es decir, es una novela que tiene que abrirse un espacio por cuenta, única y exclusivamente, del trabajo disciplinado del autor. Gutiérrez Girardot considera que el escritor canonizado es "un narrador que confía demasiado en la fuerza de la anécdota sorprendente y en su capacidad de invención”, mientras que el otro (Moreno-Durán) agrega — a las anteriores cualidades - "el trabajo de taller, si por esto se entiende no solo la elaboración de la prosa, sino igualmente la documentación y la lectura” (Gutiérrez Girardot, 1981b, p. 67). Son varios los aspectos aludidos por el autor respecto a las dos novelas, pero no hace falta mencionarlos. Basta con decir que realizó algunas críticas a Crónica de una muerte anunciada, sin desconocer la capacidad narrativa de su autor. Es suficiente mencionar la valentía y cierto atrevimiento del autor al publicar el artículo en una revista cuyos lectores latinoamericanos y españoles habían hecho de García Márquez un monumento del boom literario del continente. Este es un gesto que agradece el escritor, pues para él significa un compromiso con el crítico, en el sentido que siente la necesidad de seguir trabajando para no defraudarlo (Moreno-Durán, s.f.a).

Lo anterior, obviamente, va a impactar en el público lector que empezará a preguntarse por la obra de ese colombiano. O también en un público lector que no estará de acuerdo con la posición de Gutiérrez Girardot. Ricardo Cano Gaviria (1982), por ejemplo, escribió una crítica al artículo de Gutiérrez Girardot en la sección de opinión de la misma revista (número 16), en la que consideraba que la comparación entre los dos escritores era exagerada y que García Márquez había servido como “pantalla para una más efectiva o expedita entronización” de Moreno-Durán (p. 63). Por supuesto, Rafael Gutiérrez Girardot contestó, también en la sección de opinión, a Cano Gaviria. La polémica no trascendió, pero resonaría en el ambiente intelectual de la época.

El profundo deseo de Moreno-Durán por ser considerado un escritor del postboom se percibe cuando le menciona a su amigo que García Márquez es cómplice de las editoriales en la pretensión de dejar un heredero comercial de su obra en Colombia. Este es el caso de Luis Fayad, frente al cual no tienen nada que decir, exceptuando que es el elegido por García Márquez para ser su sucesor al trono de la fama. Este sentimiento se justifica por el hecho de que, para él, Fayad no había producido, para los primeros años de la década del ochenta, una obra extensa como la suya. García Már- 
quez ha invitado a Luis Fayad a Colombia para que haga lanzamiento de su "única" novela en la editorial Oveja Negra. Este parece ser un chisme entre editores: Carmen Balcells le comenta a Miguel Riera y este, a su vez, le transmite a Moreno-Durán, quien termina desahogándose con su crítico literario. Según Moreno-Durán, Balcells le tiene un sueldo mensual a Fayad para que este escriba su obra maestra, que la editora española publicará con la ayuda de García Márquez (Moreno-Durán, 1985a). En este sentido, la respuesta de Gutiérrez Girardot es contundente e iluminadora, y tiene tono de regaño, pues piensa que Moreno-Durán no puede ser el sucesor de un monarca, porque esto lo vuelve perezoso intelectualmente: "si él [García Márquez] lo hubiera escogido a usted para 'promoverlo' en nuestra locombia, eso no hubiera sido un gesto de ecuanimidad, sino una manera de liquidarlo" (Gutiérrez Girardot, 1984). Moreno-Durán está pensando con la lógica de la vida intelectual, sabe que "luego" del gran boom de García Márquez hay un espacio intelectual y comercial por llenar, y sabe que el asunto es de estrategia.

En consecuencia, podemos decir que la obra de Moreno-Durán no se explica bajo el binomio "vida y obra” (Dosse, 2011, pp. 53-70), tan común a los positivistas, sino que muestra que las relaciones y las tensiones intelectuales también contribuyen a la construcción de esta. En este caso - y viendo la estrecha relación entre ambos autores - podríamos decir que Gutiérrez Girardot también es el autor (al margen) de la obra y la trayectoria de Moreno-Durán. El crítico literario insta al escritor a escribir sobre determinados temas. Primero le sugiere cambiar el tema de la novela feminista por el de novela histórica, le da opciones de personajes históricos (uno es el poeta del modernismo colombiano José Asunción Silva); luego le menciona a Humboldt y su periplo por Colombia. Estas sugerencias no son pasivas: están acompañadas de una buena bibliografía y de fuentes históricas. Adicionalmente, le recomienda novelas históricas como modelos óptimos: estos son los casos de La muerte de Virgilio de Hermann Broch o José y sus hermanos de Thomas Mann. Gutiérrez Girardot creía que la novela histórica era un género por explorar en los escritores colombianos.

Estas sugerencias son también una especie de preámbulo a lo que pretende publicar Gutiérrez Girardot. Todo lo que va a decir públicamente el crítico literario es leído previamente por Moreno-Durán en las epístolas que le envía su amigo. Este es el caso de su proyectado ensayo sobre la trilogía Femina Suite, en el cual Gutiérrez Girardot le anuncia: 
Yo lo considero como un ciclo cerrado que ha agotado el tema de la guerra sexual, con todas sus múltiples concomitancias. Encuentro que lo que sigue en esta línea, solo puede ser repetición, es decir, trivialidad. Quiere usted seguir el mismo camino de García Márquez? Eso es anacrónico. Usted no es la especie de los Álvarez Gardeazabal. Y la realidad es que el caso de Silva es lo más complicado que usted pueda imaginarse, es complejísimo y exige conocimientos e investigaciones más amplias. Lea el poema conjetural de Borges, piense en el destino de Sarmiento, de Julián de Casal, de César Vallejo, etc, etc, no, el material no es fácil. Fácil es el tema de la guerra de los sexos (Gutiérrez Girardot, 1984).

Es de este modo como la narrativa de Moreno-Durán adquiere un nuevo rumbo. Acepta que la guerra de sexos como tema literario está agotado y comenta a Gutiérrez Girardot su nuevo proyecto literario sobre la vida diplomática, dado que Silva es un tema que está pendiente: es decir, el nuevo rumbo de Moreno-Durán es la novela histórica. Durante casi cuatro años, entre 1984 y 1987, el escritor comenta epistolarmente a Gutiérrez Girardot los avances investigativos en torno al tema de la obra que se llamará Los felinos del Canciller. Por el momento, Moreno-Durán se hace dos preguntas conclusivas: “¿Por qué no hay una narrativa de la diplomacia en lengua española? ¿Acaso porque la ambición secreta de todo escritor es ser diplomático?” (Moreno-Durán, 1985b).

Luego de un año, Moreno-Durán expresa los logros críticos que va obteniendo con esta novela. El escritor boyacense considera que, si en su trilogía fue cruel con la cultura de la clase media de su país, en la novela que está pronta a ser publicada es cruel, mediante la crítica filológica, con los patricios de su país que abusaron de la oralidad como mecanismo para que su "estolidez" pasase desapercibida (Moreno-Durán, 1986a).

El trabajo de Gutiérrez Girardot sobre Los felinos del Canciller aparece publicado en una segunda versión de su libro Provocaciones (1997) con el título de "La crítica a la aristocracia bogotana en Gabriel García Márquez y R. H. Moreno Durán”. En él, el crítico continúa con la estrategia de ubicar a Moreno-Durán al lado de García Márquez. Este escrito se diferencia del anterior en el hecho de que Gutiérrez Girardot se expresa admirativamente de Cien años de Soledad (como de alguna manera lo hace en el escrito anterior) y pone de presente la agudeza crítica de los dos autores al ocuparse de un tema poco trabajado en la literatura hispanoamericana como es el de las aristocracias. García Márquez caricaturiza a la aristocracia bogotana a través de Fernanda del Carpio. Ella tipifica la pretensión de ciertos grupos sociales por ser "aristócratas", pero confrontando esa pretensión con la realidad de una aristocracia en proceso de 
empobrecimiento que, sin embargo, celebra ritos que muestran la obsesión de estos grupos sociales por mantener el statu quo de una sociedad altamente jerarquizada. Lo que critica García Márquez es la ficción en la que están envueltos personajes como Fernanda del Carpio al estar de espaldas a la realidad. Por su parte, en Los felinos del Canciller, Moreno-Durán muestra el acomodamiento de las familias aristocráticas en la vida diplomática. La opulencia que en el siglo Xıx tenían familias como los Barahona es sostenida, en el siglo xx, gracias a ocupaciones en las que no se hacía nada. Mientras el padre de Fernanda del Carpio teje "palmas fúnebres" para esconder su pobreza, Félix Barahona es nombrado “consejero itinerante”(Gutiérrez Girardot, 1997, p. 194), trabajo cuya función solo era conocida por él. Tanto el abuelo de Félix, Gonzalo, como su padre, Santiago, habían estado en el servicio exterior. Para Gutiérrez Girardot, estos son un tronco familiar que ha vivido de la falsificación, del anacronismo.

Pese a las dudas respecto al concepto de postboom por parte del crítico colombiano, Moreno-Durán insiste en darle insumos para que este no vacile ni un momento en realizar la tarea sugerida. Por ejemplo, le enumera cada uno de los logros que tienen sus novelas. No solo están los éxitos en España, sino también los obtenidos en Estados Unidos (Moreno-Durán, 1985a). Además, está Teo A. Noriega, profesor en Toronto (colombiano), quien realizará primero una ponencia y luego un libro derivado de la misma (Moreno-Durán, 1986b). Moreno-Durán le habla de una serie de condiciones que indican que un nuevo escritor colombiano (él mismo) se está abriendo las puertas internacionales.

Es difícil precisar si Moreno-Durán fue o no un escritor del canon de la literatura latinoamericana: a veces parece un escritor olvidado. El valor que pueda tener se apreciará cuando hayan pasado muchos años de su muerte y se hayan hecho los balances de la historia de la literatura colombiana y latinoamericana recientes. Ahora solo se puede estar seguro de los importantes premios con los que fue galardonado y las editoriales reconocidas que publicaron su obra. Nos referimos a Montesinos, Alfaguara, Planeta, etc. Además, y como ha mostrado Susana Zanetti (1998), Latinoamérica no tiene mecanismos sólidos mediante los cuales se establece el canon, en parte por la falta de una especie de "academia supranacional que se plantee como voz autorizada, cuyos dictámenes pondrían a prueba las nuevas generaciones de lectores” (p. 92). Gutiérrez Girardot es rico en interpretaciones críticas, pero no representa esa academia supranacional. Lo que resulta interesante en este caso es comprender los mecanismos 
extrapoéticos utilizados por los dos boyacenses, conscientemente, para buscar la legitimidad de una nueva obra. Estos mecanismos son evidentes gracias al epistolario.

Entonces, puede decirse con claridad que la obra de Moreno-Durán fue hecha también en compañía de Rafael Gutiérrez Girardot. El mismo Moreno-Durán lo reconoce en muchas ocasiones. Cuando se inició la correspondencia, el escritor solo había publicado un libro de ensayos titulado De la barbarie a la imaginación; es decir, Gutiérrez Girardot vive todo el proceso de maduración intelectual de su amigo.

Es significativo que este libro de ensayos tenga cinco ediciones, de las cuales hay un cambio importante entre la primera y la tercera. Solo la última es reimpresión. La primera aparece en la editorial Tusquets (1976), la segunda en Tercer Mundo Editores (1988), la tercera en Editorial Ariel (1996), la cuarta en el Fondo de Cultura Económica (2004) y la quinta en edición póstuma por la Universidad de los Andes. Esta larga historia, de casi treinta años, en la transmisión de un libro muestra que Moreno-Durán siempre estaba en la disposición de mejorar sus obras porque pensaba que estas nunca estaban terminadas.

Pero lo más significativo es que este libro demuestra, como la ha dicho Pierre Bourdieu (1969), que la producción intelectual no es el resultado de la inspiración de un autor, en el aislamiento de su cuarto, ni consecuencia del genio creador, sino más bien resultado de la posición que ocupa el creador en medio de las relaciones y tensiones de fuerza del campo intelectual (pp. 135-182). Esto se puede decir porque el desarrollo de este libro es también consecuencia de la estrecha relación de los autores de nuestro interés. Con motivo del primer artículo que le envió Rafael Gutiérrez Girardot a Moreno-Durán para un dossier de literatura latinoamericana en la revista Camp de L'Arpa que se ha mencionado más atrás, Moreno-Durán escribe no solo para notificar la recepción del artículo, sino también para expresar la impresión que dicho artículo le ha causado, especialmente porque siente que su libro De la barbarie a la imaginación fue escrito bajo el influjo de teorías juveniles. A este respecto Moreno-Durán dice:

[...] yo mismo me siento vapuleado críticamente y eso es muy importante, pues creo que si algo debo revisar de mi ensayo De la barbarie a la imaginación es haber aceptado en mi entusiasmo juvenil teorías a las que no sometí previamente, el siempre útil "beneficio de inventario". Ya le había escrito yo sobre mi deseo de corregir a fondo ese libro y espero que, en el futuro, cuando me decida a hacerlo, cuente con su valiosa colaboración en este aspecto (Moreno-Durán, 1978c). 
Siguiendo a Bourdieu, podríamos afirmar que ese libro es también escrito por $\mathrm{Gu}-$ tiérrez Girardot o por la tradición a la que pertenecen Gutiérrez Girardot y Moreno-Durán. Cuando Moreno-Durán va a Colombia en 1986, aprovecha la oportunidad para reescribir el libro al tenor de las lecturas y notas que ha realizado después de diez años de su primera edición, muchas de las cuales han sido recomendaciones de Gutiérrez Girardot, no solo directamente, sino también gracias a las lecturas qua ha hecho de los escritos del ensayista boyacense. Para esta fecha, ha firmado el contrato con Procultura y espera terminarlo en febrero de 1987. Este es también un proceso en el que constantemente interactúa con su amigo. Aunque en enero de 1987, el escritor expresa que ya se pueden referir a la obra de Moreno-Durán en sentido estricto - ha escrito varios libros de ficción y un libro de ensayos-, en la carta se percibe que el autor considera que De la barbarie a la imaginación es una obra inconclusa. ¿Será que piensa que tiene una deuda con su modelo ensayístico, Rafael Gutiérrez Girardot? "De ahí la minuciosa, delirante revisión (rescritura) De la barbarie a la imaginación: ni una sola página se ha salvado de la revisión: quince años después mis ideas son no solo más sólidas, sino también más claras” (Moreno-Durán, 1987). Y más adelante agrega:

[...] el mes o dos meses de corrección que pensaba invertir en De la barbarie a la imaginación me devolvieron a la realidad y el libro me ganó de tal forma que lo rescribí por completo: eliminé antiguos entusiasmos, afilé la crítica y puse orden a las cosas. Tras quince años de la primera edición muchas cosas han cambiado, sobre todo yo mismo [...]. He trabajado a fondo en la infraestructura ensayística: Sarmiento, Rodó, Henríquez Ureña, Vasconcelos y Reyes, así como Romero y otros, me han afianzado el pulso y ratifican buena parte de mi enfoque: lo que antes estaba apenas sugerido hoy esta abiertamente asumido o refutado (Moreno-Durán, 1987).

Esta es una declaración de fe, por parte de Moreno-Durán, en lo que respecta a los modelos ensayísticos que había definido Gutiérrez Girardot hasta ese momento. Los autores citados por Moreno-Durán en la anterior epístola son, exceptuando a Vasconcelos, los que Gutiérrez Girardot ha definido como los arquitectos de América y los grandes modelos ensayísticos del continente. Esta es una confesión, a su maestro, en la que se deja constancia de que ese libro de 1977 era el de un escritor en formación, y que ahora está preparado para la edición madura, porque estos años los ha pasado al lado de la lectura de la obra de Rafael Gutiérrez Girardot, sus cartas y proyectos comunes.

Luego de un receso, de algunas reediciones de sus libros, Moreno-Durán empieza a vislumbrar su nuevo tema. Inicialmente piensa en un personaje que había sugerido Gutiérrez Girardot: Humboldt. El libro se llamará El caballero de la invicta 
(Moreno-Durán, 1988). Este tema es fundamental, pues acerca al escritor colombiano a la trama alemana y, mucho más, a su amigo Gutiérrez Girardot, quien con esta orientación le abriría la posibilidad de que en Berlín le financiaran una estancia de investigación en tanto que la figura de Humboldt seguramente interesaría a las instituciones alemanas. La beca no se obtuvo y la situación fue una de las razones para que Moreno-Durán reiteradamente se quejara de la mala suerte que tenía para obtener este tipo de reconocimientos.

\section{Colombia: la patria de Moreno-Durán y Gutiérrez Girardot}

Colombia es un tópico que no puede pasarse por alto en la correspondencia entre estos intelectuales. Su país de origen está en el horizonte de reflexión y es constantemente aludido por ellos. En primera instancia, porque ambos autores sienten que han sido marginados de la escena intelectual colombiana, pero, además, porque ambos quieren ganarse un espacio y sobre todo conquistar un público lector en su país. Para Moreno-Durán es un infortunio que mientras El País de España ha seleccionado su novela Finale Capriccioso con Madonna (1982) como uno de los libros latinoamericanos del año (lo mismo que hicieron con Juego de damas y El toque de Diana, sus otras dos novelas), en Colombia su trabajo pase casi desapercibido: que "mi propio país me dé la espalda (salvo una breve reseña de Gómez Valderrama), ni una sola nota ha salido en Colombia sobre mi último libro, y eso que ha pasado casi un año" (Moreno-Durán, 1984). La queja constante apuntaba al poco reconocimiento que tenía en su país, mientras que en España sus novelas siempre eran bien recibidas por la prensa. Esto quizás se deba a que su centro de operaciones era Barcelona y desde ahí se podía mover, como se mostró en la primera parte de este artículo, en diferentes medios intelectuales.

En este sentido, la vida intelectual del país es un tema fundamental del epistolario. En casi todas las epístolas sueltan algún comentario crítico sobre un escritor colombiano. Por ejemplo, Sanín Echeverri es atacado por Gutiérrez Girardot por dárselas de listo. Según el ensayista, Sanín Echeverri hizo un álbum de los recortes de prensa de su revista Arco y las envió a las agencias de noticias europeas, para hacerla pasar como la mejor revista de Latinoamérica. Moreno-Durán no pierde oportunidad para criticar a Óscar Collazos porque, según él, en todo momento se le atraviesa en el camino. Ambos creen que Juan Gustavo Cobo Borda es un consentido del Estado. Cabe recordar que este ensayista tiene una posición de poder en el campo de 
la cultura colombiana: trabajó en el Instituto Colombiano de Cultura (1975-1983) y fue agregado cultural de Colombia en Argentina. Además dirigió revistas literarias como Eco y Gaceta. Así es que tanto Moreno-Durán como Gutiérrez Girardot están luchando por un espacio intelectual en su patria, espacio que al parecer está copado por personajes como Óscar Collazos, Juan Gustavo Cobo Borda, Luis Fayad y, desde luego, Gabriel García Márquez. De este modo, tratan también de construir símbolos de pertenencia en torno a la literatura colombiana.

En el epistolario salen a flote no solo el amor patrio, sino los resentimientos que ambos tienen hacia la cultura colombiana y ciertos círculos intelectuales. En este caso la relación también gira en torno al reconocimiento mutuo como portadores de independencia intelectual frente a las instituciones culturales y estatales colombianas y los intelectuales cercanos a ella. Los dos autores critican la "pobre vida intelectual" del país. Lo anterior, obviamente, desde su perspectiva, la cual está signada, en la década de los ochenta, por la independencia frente al Estado colombiano y sus instituciones culturales. Entre ellos mismos se asumen como los portadores de la definición de la literatura colombiana independiente del poder estatal y económico, o lo que Pierre Bourdieu (1995) llamaría una jerarquización interna del campo literario que significa la legitimación de los valores estéticos independientes del campo del poder como expresión de la autonomía intelectual (pp. 321-322). La lucha de estos dos personajes es en contra de las instituciones que dominan el espectro cultural del país representadas en figuras particulares como la de Juan Gustavo Cobo Borda, e indirectamente, Gabriel García Márquez.

En el epistolario de los dos colombianos aparecen figuras e instituciones de la cultura colombiana a las cuales dan ciertas membresías, pero también otras a las que quieren excluir de esta. Si son implacables con figuras como Óscar Collazos - especialmente R. H. Moreno-Durán, que no pierde ocasión de criticarlo-, el caso de García Márquez y Luis Fayad es diferente. El escritor y el crítico se sienten incómodos con el hecho de que luego de que el primero se haya ganado el Nobel, solo quiera seguir viviendo del nombre y del monumentalismo; pero sobre todo critican el hecho de que este escritor tenga un vínculo comercial y estrecho con las editoriales, que utiliza para que el segundo sea lanzado a la fama como el escritor colombiano que habrá de reemplazarlo. Se puede sostener que los dos autores son conscientes de que el éxito de su producción intelectual depende del resultado de las relaciones de fuerza en esa tensión con el poder de las editoriales. 
El inconformismo de ambos intelectuales se enfila no solo contra otros escritores, sino también contra las editoriales, en las que recae la responsabilidad por el "fracaso" de la literatura colombiana. Moreno-Durán piensa que, para el año de 1981, hay una joven narrativa "enteca" debido a que editoriales como Plaza y Janés, por negocio, editan y premian lo que se publica en la "provincia”. El problema de esta joven literatura colombiana es que siempre gira sobre los mismos temas: "violencia, líderes estudiantiles y guerrillas" (Moreno-Durán, s.f.b).

Todo lo anterior no impide que la relación de los dos personajes con Colombia cambie positivamente. Paradójicamente, el cambio tiene que ver, en parte, con el regreso de Moreno-Durán a su país en 1986. Decimos paradójicamente, porque el paso de este escritor por Colombia era momentáneo, pues la posibilidad de vivir allí, instalado, era inconcebible para él. No obstante, luego de intentar viajar a otros lugares sin éxito se conforma, reconcilia y hasta se adapta a la nueva situación. Por ejemplo, en enero de 1987 Moreno-Durán está pensando que el trabajo intelectual cuando está instalado en Colombia es liberador, en el sentido de que lo abstrae del complejo orden público de esa sociedad "que se le escapó a Dante". No obstante, siente esto como un nuevo aprendizaje porque no entiende muchas cosas del país del que proviene. Allí vivirá con pocas interrupciones hasta su muerte y la correspondencia enviada a Gutiérrez Girardot será emitida desde Bogotá, el centro de sus operaciones intelectuales.

Pasado un tiempo, Moreno-Durán celebra que la revista Aleph hable maravillas de Gutiérrez Girardot y que además publique una de sus entrevistas: "Ya es tiempo de que en Colombia se te brinde la atención que mereces, al menos para que no vuelvan a incurrir en los feos incidentes que narras y que pintan a nuestra clase intelectual" (Moreno-Durán, 1986c). Luego le comenta que se siente muy complacido con el hecho de que haya gente joven que aprecie la labor intelectual y de crítica literaria de Gutiérrez Girardot. Hace referencia específica a ciertos estudiantes de la Universidad Nacional y a la revista Argumentos dirigida por Rubén Jaramillo Vélez y en la que Gutiérrez Girardot empezó a ser colaborador asiduo. Moreno-Durán habla como un estratega cuando le dice: "no descubras ese frente" (Moreno-Durán, 1986d).

La estancia de Moreno-Durán en Bogotá significa para él un redescubrimiento de Colombia, pero sobre todo la posibilidad de negociar la reedición de sus obras y la oportunidad de encontrar al público colombiano que siempre había esperado. 1987 
será el año editorial de Moreno-Durán, pues está reeditando sus obras en España y en Colombia. Esto también significa la apertura de un nuevo espacio para Gutiérrez Girardot en su país. Moreno-Durán ha entrado en contacto con Álvaro Mutis, quien quiere hacer una nueva revista e invita, a través de él, a Gutiérrez Girardot, con la idea de que este último trabaje en los temas literarios. La presencia del crítico literario en Colombia será mucho más dinámica. Él será invitado a Colombia en diferentes oportunidades y, por supuesto, definido como un especialista en temas colombianos. Lo entrevistan en medios intelectuales como Aleph. Moreno-Durán hace seguimiento riguroso a la recepción del crítico, pues le interesa abrirle un espacio de atención al profesor de la Universidad de Bonn.

Vale la pena aclarar que dicho interés también apunta a ganarse un espacio para sí mismo. Moreno-Durán ha entrado en contacto con la Editorial Planeta y, según él, le han solicitado un texto de Gutiérrez Girardot sobre un tema libre. Dado que, luego de la muerte de Ángel Rama nadie se ha preocupado por la narrativa del postboom, Moreno-Durán vuelve e insiste en que este sería el tema más pertinente (Moreno-Durán, 1989). ¿Por qué la insistencia? ¿Quiere que se publiquen ensayos en los que aparezca su nombre? Moreno-Durán argumenta diciendo que el tema le daría un carácter universal a su escrito, pues para la época hay un grupo de literatos latinoamericanos como Fernando del Paso, José Emilio Pacheco, Bryce Echenique y Manuel Puig que tiene sus ventas en Colombia. Sin ninguna duda, la propuesta lleva implícito el deseo de afirmar el concepto de postboom en Colombia desde una editorial comercial (Moreno-Durán, 1989). Lógicamente, Moreno-Durán, sin expresarlo textualmente, no quedaría excluido de este selecto grupo de escritores.

Se puede decir entonces que, para finales del siglo xx, la tarea de Moreno-Durán ha sido, más o menos, cumplida. Así lo expresa en sus cartas de esta etapa. No solo logra ganarse un espacio en la vida intelectual colombiana, sino que puede aplaudir que Rafael Gutiérrez Girardot, de algún modo, también lo haya hecho. Los méritos de Gutiérrez Girardot son indiscutibles, pero no se puede desconocer que Moreno-Durán trabajó también en este sentido. El tópico de una carta de 1999 versa sobre la lista de los cien mejores libros del siglo xx en Colombia publicada por la revista Semana. Gutiérrez Girardot aparece dentro de los 20 primeros con su libro Modernismo, en la categoría ensayo. Moreno-Durán igualmente en categoría novela (Moreno-Durán, 1999). 
Esta es, apenas, una parte de la relación epistolar fructífera de la que aún quedan muchas cosas por decir. Cuando se estaba realizando esta investigación, el archivo personal de Moreno-Durán no estaba organizado. Hay aspectos de esta investigación aún inéditos y otros que quizás se puedan completar cuando se tenga acceso a la totalidad de la correspondencia.

\section{Referencias bibliográficas}

Aguilar, G. (2010). Los intelectuales de la literatura: cambio social y narrativas de identidad. En C. Altamirano (Dir.). Historia de los intelectuales en América Latina (T. 2, pp. 685-711). Buenos Aires: Katz. Bourdieu, P. (1969). Campo intelectual y proyecto creador. En J. Campos, G. Esteva, A. de Ezcurdia (Trad.). Problemas del estructuralismo (pp. 135-182). Madrid: Siglo Veintiuno Editores.

Bourdieu, P. (1995). Las reglas del arte. Génesis y estructura del campo literario. Barcelona: Anagrama.

Cano Gaviria, R. (1982). Tres veces humor. Quimera 16, p. 63.

Collins, R. (2005). Sociología de las filosofías. Barcelona: Hacer Editorial.

Dosse, F. (2011). El arte de la biografía. México: Universidad Iberoamericana.

Gutiérrez Girardot, R. (1980). [Carta a Rafael Humberto Moreno-Durán] Bonn, 18 de mayo. Copia alojada en el APJGGG.

Gutiérrez Girardot, R. (1981a). [Carta a Rafael Humberto Moreno-Durán] Bonn, 21 de diciembre. Copia alojada en el APJGGG.

Gutiérrez Girardot, R. (1981b). Dos veces humor (G. García Márquez. Crónica de una Muerte Anunciada. R.H. Moreno Durán El toque de Diana). Quimera 14, pp. 67-70.

Gutiérrez Girardot, R. (1984). [Carta a Rafael Humberto Moreno-Durán] Bonn, 18 de enero. Copia alojada en el APJGGG.

Gutiérrez Girardot, R. (1997). La crítica a la aristocracia bogotana en Gabriel García Márquez y R.H. Moreno-Durán. En Provocaciones (pp. 173-200). Bogotá: Editorial Ariel.

Moreno-Durán, R.H.(1978a). [Carta a Rafael Gutiérrez Girardot] Barcelona, 1 de junio. Copia alojada en el APJGGG.

Moreno-Durán, R. H. (1978b). [Carta a Rafael Gutiérrez Girardot] Barcelona, enero. Copia alojada en el APJGGG.

Moreno-Durán, R. H. (1978c). [Carta a Rafael Gutiérrez Girardot] Barcelona, 10 de agosto. Copia alojada en el APJGGG.

Moreno-Durán, R. H. (1981). [Carta a Rafael Gutiérrez Girardot] Barcelona, 26 de febrero. Copia alojada en el APJGGG. 
Moreno-Durán, R. H. (1984). [Carta a Rafael Gutiérrez Girardot] Barcelona, 3 de enero. Copia alojada en el APJGGG.

Moreno-Durán, R. H. (1985a). [Carta a Rafael Gutiérrez Girardot] Barcelona, 10 de enero. Copia alojada en el APJGGG.

Moreno-Durán, R. H. (1985b). [Carta a Rafael Gutiérrez Girardot] Barcelona, 15 de abril. Copia alojada en el APJGGG.

Moreno-Durán, R. H. (1986a). [Carta a Rafael Gutiérrez Girardot] Barcelona, abril. Copia alojada en el APJGGG.

Moreno-Durán, R. H. (1986b). [Carta a Rafael Gutiérrez Girardot] Barcelona, 2 de enero. Copia alojada en el APJGGG.

Moreno-Durán, R. H. (1986c). [Carta a Rafael Gutiérrez Girardot] Barcelona, 1 de abril. Copia alojada en el APJGGG.

Moreno-Durán, R. H. (1986d). [Carta a Rafael Gutiérrez Girardot] Barcelona, 25 de noviembre. Copia alojada en el APJGGG.

Moreno-Durán, R. H. (1987). [Carta a Rafael Gutiérrez Girardot] Barcelona, marzo. Copia alojada en el APJGGG.

Moreno-Durán, R. H. (1988). [Carta a Rafael Gutiérrez Girardot] Barcelona, 2 de abril. Copia alojada en el APJGGG.

Moreno-Durán, R. H. (1989). [Carta a Rafael Gutiérrez Girardot] Barcelona, 2 de abril. Copia alojada en el APJGGG.

Moreno-Durán, R. H. (1999). [Carta a Rafael Gutiérrez Girardot] Barcelona, 20 de octubre. Copia alojada en el APJGGG.

Moreno-Durán, R. H. (s.f.a). [Carta a Rafael Gutiérrez Girardot] Barcelona, 22 de octubre. Copia alojada en el APJGGG.

Moreno-Durán, R. H. (s.f.b). [Carta a Rafael Gutiérrez Girardot] Barcelona, 30 de diciembre. Copia alojada en el APJGGG.

Myers, J. (2014-2015) El epistolario como conversación humanística: la correspondencia intelectual de Alfonso Reyes y Genaro Estrada (1916-1939). Politicas de la memoria 15, pp. 53-69.

Ozuna Castañeda,M. (2017). Epistolario del ensayo, ensayismo de la epístola. En L. Weinberg (Coord.). El ensayo en diálogo (T. 1, pp. 263-289). México: Universidad Autónoma de México.

Williams, R. (1980). Marxismo y literatura. Barcelona: Ediciones Península.

Zanetti, S. (1998). Apuntes acerca del canon latinoamericano. En S. Cella (Comp.). Dominios de la literatura. Acerca del Canon (pp. 87-105). Buenos Aires: Losada. 